\title{
Computing Academics' Perceived Level of Awareness and Exposure to Software Engineering Code of Ethics: A Case Study of a South African University of Technology
}

\author{
Robert T. Hans ${ }^{1}$ \\ Department of Computer Science \\ Tshwane University of Technology \\ Soshanguve, South Africa
}

\author{
Senyeki M. Marebane ${ }^{2}$ \\ Faculty of ICT \\ Tshwane University of Technology \\ eMalahleni, South Africa
}

\author{
Jacqui Coosner $^{3}$ \\ Operations Department \\ Incusdata, Centurion \\ South Africa
}

\begin{abstract}
The need for awareness on ethical computing is increasingly becoming important. As a result this challenges all stakeholders in the software engineering profession, including educators, to improve their efforts on the awareness of professional codes of ethics which provide framework for ethical reference. However, the several compromises in the software engineering practice suggest that there are some in the profession, who are not familiar with the profession's codes of ethics and subsequently not able to practice and teach students about them. This research work investigates the extent of codes of ethics awareness by practitioners who are teaching software development courses in an academic environment. An online questionnaire with indicators for measuring awareness on software engineering code of ethics was deployed and responded to by 44 educators. Graphical, univariate and bivariate analyses were conducted on the data to determine the profile of the respondents and the extent of their level of awareness on the codes of ethics. The results indicate that majority of the lecturers (54.5\%) are not aware of software engineering codes of ethics, and those who are aware, majority of them were exposed to through self-study or personal development. Furthermore, the inclusion of codes of ethics in the learning activities is minimal as inhibited by lack of awareness and failure to apply the codes practically. This study recommends that lecturing staff as part of the professional software engineers serving as academic corps, should be placed on programmes for exposing them to professional software engineering codes of ethics. Moreover, the study calls for accreditation of software engineering courses, as it is the case with other professional engineering disciplines, to improve awareness and subsequent practical application of the codes of ethics.
\end{abstract}

Keywords-Software engineering ethics; code of ethics; ethics awareness; ethics education; moral development ethics

\section{INTRODUCTION}

Awareness of the ethical implications of computing by educators in software engineering is increasingly becoming important. This is due to the responsibility educators have to prepare students to practice the trade in a way that reflects ethicality in their technical work [1]. Therefore, educators' role is significant to heighten the efforts in the teaching of ethics in technology courses [2] especially that they are also regarded as software engineers with a duty to promote the profession [3]. Improved efforts in education specifically about the ethical implications of developing software products are more required, as software has evolved to a de facto virtual resident in all areas of human lives due to the indispensable role it plays in devices and systems used by society. Software has contributed immensely to humanity, starting from promotion of human rights through social media [4], operation of machines in dangerous zones such as underground mines [5], saving of lives through computer aided surgeries [6] and usage of artificial intelligence to discover and discern patterns useful in understanding complex situations [7]. However, the list of software ethics violations such as wrongful use of software [8], deployment of badly designed and insufficiently tested software that created catastrophes such as aircraft crashes [9], [10], social media platforms used to drive misinformation for propaganda [11] even misinformation on global health pandemic such as Covid-19 [12] is continuing to haunt the province of computing ethics education. It specifically challenges the capacity of teaching software engineering ethics about the ethical awareness of those who teach software engineering and their ability to practicalise ethics into the curriculum.

Software engineering endeavours consider ethics education as an integral part of the moral development agenda, which, positively contribute to ethical computing awareness [1], [13]. For the software engineering ethics education to flourish, those involved in the teaching should be aware of the codes of ethics [3] as ethics navigation tool, infrastructure and content for teaching ethics. They should also create learning opportunities to assist students to practically internalize the codes alongside their other sources of ethical reference such as personal codes [14]. These opportunities can provide a rich experience on ethical awareness and ethical pluralism. Several frameworks for teaching ethics in computing advocates for the integration of codes of ethics into the curriculum [15]-[19]. These codes of ethics express a profession's disposition on ethics and professionalism, spells out principles to guide professionals and educates the professionals about what the society should hold them accountable for [20]. Therefore, the embracing of ethical codes by those involved in the education 
of software development can significantly contribute to the improvement of ethical awareness of the future graduates. It is on that note that Barnard et al [17] advocate that the teaching of ethics concepts and actions that underpin them should be integral part of the training of any future ICT professional. Therefore, those involved in the teaching of software development should be aware of the profession's ethics so they that can be in a position to teach the students accordingly.

The purpose of this study is to establish the extent to which university lecturers who are involved in teaching of software development courses in a South African University of Technology (UoT) are aware of software engineering ethics code. To help achieve this purpose the following research question and objective were formulated:

\section{Research question:}

What is the computing academics' level of awareness and exposure to a code of ethics specific to software engineering?

\section{Research objective:}

To determine computing academics' level of awareness and exposure to a code of ethics specific to software engineering.

This study helps to understand the extent of awareness on code of ethics in environments for teaching software development courses by measuring awareness by lecturers. Based on the awareness results, lecturers, industry trainers and employers will have better understanding of their insufficient knowledge of codes of ethics and the subsequent need for improvement. It will also help lecturers in faculties and organizations providing training on software engineering courses to realize the significance of using codes of ethics and the alignment thereof to real life incidents of ethical issues (good and bad), as well as including the codes in the constructive alignment activities related to teaching and learning of software engineering.

\section{LITERATURE REVIEW}

\section{A. The Need to Teach Ethics and the Role of Education on Moral Development}

The need for ethics in computing dates back to the days of the need for analysing the nature and social impacts of computing technology, and policies to clarify the ethical use of such technology [21]. However the challenge has always been the lack of practical knowledge and skills on how to apply ethics when faced with dilemmas [22]. University lecturers form an integral part of the ethics awareness program through the role they play in teaching software engineering ethics; and also serving as ethical examples. Therefore, institutions of learning should form the centre of efforts to be evaluated on their effect on moral development of students [23], especially faculty staff who participates in the teaching of ethics in educational environments.

Academic institutions like UoTs contribute to the software engineering business by providing education to graduates who work in the industry. Therefore, it is important for university lecturers to be aware of codes of ethics and include them as part of content used to orientate students about the expectations of software engineering profession in their teaching activities. Though it seems difficult and impossible, Kohlberg and Hersh [23] submit that the teacher bears the responsibility to guide the student to embrace practical moral conflicts, consider various sources for ethical reasoning, contrast personal thinking inconsistencies and inadequacies and means to address them. Several authors identify numerous instructional strategies for adoption in teaching ethics, such as online and face to face classroom discussions [24], writing of codes of ethics [25], service learning and civic engagement [26] case studies [27], evaluation of own project design [28], discussion on case studies and codes of ethics [19] and a combination of various strategies amongst others.

\section{B. Teachers as Facilitators of Ethical Awareness}

Research has proven the lack of required skills by ICT professionals to adequately apply moral judgements at work [29]. This challenges the adequacy and effectiveness of teaching computer ethics. Teaching staff as software engineers themselves, are obligated to promote ethical and professional approach to the practice [3], [18] through curriculum endeavours and conducting themselves as real life examples. Curriculum guidelines place special emphasis on software engineering teachers to take responsibility to expose students to codes of ethics as an instrument for developing professionalism and ethical competence [30], [31].

Though Harris and Lang [26] implore teachers to ponder on the ill-preparedness of graduates on ethics, several schools of thoughts have emerged regarding the teaching of computing ethics. There are divergent views as to the background of the teachers to be involved in the teaching of ethics and the instructional models to be adopted in teaching computing ethics [2], [32]. In response to these questions, in his essay Tavani [32] captures scholarly views of intellectuals like Jonhson, Dianne and Gotterbarn, whose works provided a detailed engagement on these questions.

Firstly, on the question of who can teach ethics better, it is believed that if the teaching of ethics is sourced from outside the faculty such as from philosophy experts, students may not seriously regard the subject as it may not appear to be mainstream [33]. Secondly, some believe that computer scientists lack knowledge in philosophy from which ethics derive existence, which may deny students opportunities to learn from the best whilst some believe that philosophy teachers lack technical knowledge in computing [32]. Monzon and Monzon-wyngaard [33] points out that both approaches are insufficient to integrate ethics approach.

Following on the question of instructional model, some schools of thought advocate for a single compound course that solely focuses on ethics whilst others prefer for the ethics content to be spread across several computing modules according to the applicability of the topic [32]. However, studies demonstrated that a multidisciplinary approach to the teaching of ethics can immensely enrich students' experience. For example, a study by Reich et al [34] which involved instructors from different faculties and industry experts resonated well with the course outcomes. Furthermore, Huyck et al [25] show as part of diversifying the teaching of ethics, that inclusion of students from various courses in ethics course 
generates positive outcomes. In support, Towell and Thompson [27] and Skirpan et al [28] respectively show that the functioning of an integrated instruction to ethics education yields success. The fact is, relevantly qualified teachers should be allocated to the teaching of software engineering ethics, sufficient time and faculty strategies should support the development of such ethical reasoning in the software engineering graduates.

To conduct ethics education instruction, the teacher needs to be aware of ethical and social issues technology is likely to confront the society with [17]. Therefore, such awareness should go beyond just the knowledge of principles prescribed by the codes of ethics, but also competently lead students through the ethical analysis learning process [35]. Furthermore, the views on ethics and an inclination to posture in a particular way to ethics is dependent on an individual's self-worth [36], hence it becomes deducible that a teacher who is ethically aware is likely to teach ethics to students better.

\section{Research Advances on Software Engineering Code of Ethics Awareness}

Due to the evolving ethical concerns in computing, research efforts on ethics awareness and professionalism remain relevant, as observable from previous studies conducted on this subject by [36]-[41]. Factors considered in the studies as having effect on ethics awareness on practitioners included individual characteristics such as age or maturity [42], [43], membership to a professional body [19], company commitment or leadership [44]-[46], and communication and enforcement [39] amongst others. Awareness of ethical codes helps to shape a computing professional, with their inclusion in education being the leading driver of ethical awareness [42].

There are other studies on ethical awareness that were conducted outside the academic environments and they include a study by Valentine and Barnett [37], which was carried out in a sales environment and found that awareness of codes is likely to improve organizational commitment and employees exposed to ethics codes view their work environments as being ethical. For the codes of ethics to have impact, [39] indicate that a relationship needs to exist between the codes of ethics awareness, their communication and their enforcement. Therefore, organizations need to demonstrate ethical leadership and commitment [44].

In the academic environment, a study by Cheng [47] sought to understand lecturers' perceptions toward teaching business ethics, and it found that teachers with greater selfefficacy perceive themselves as inclined to teach ethics in their domain. In relation to software engineering a study by Towell [19] found that majority of educators were aware of professional codes of ethics, and belonging to professional body appeared to be key to the awareness and promotion of such codes of ethics. A follow-up study by [27] revealed that whilst majority of educators were aware of the codes, $41 \%$ indicated that teaching of ethics was largely ignored, possibly due to lesser self-efficacy.

Several studies such as those conducted by [25], [48]-[51] studied ethical awareness on students but do not determine if those who are instructing the students, do have the ethical awareness required to teach the students and what their impact is on the students. Barnard et al [17] have demonstrated that computing instructors regard the teaching of computer ethics as importantly equal to the teaching of technological topics. We, therefore find it important to determine the extent to which lecturers involved in the teaching of software development are aware of software engineering codes of ethics, which are necessary and in some cases prescribed to instruct students. Furthermore, a study by Rogerson [52] shows that only $3 \%$ of professionals in the software development industry belong to a professional body, which implies that there is a possibility that there may be many university lecturers teaching in computing within the $97 \%$ who are not aware of the codes of ethics because they do not belong to a professional body.

This research study extends on the above studies as it analyses an environment of teaching software development, particularly in a UoT, in order to determine the extent to which a faculty is aware of software engineering codes of ethics.

\section{RESEARCH METHODOLOGY}

Online survey was utilized to collected data used in this study. The collected data formed part of a research project aimed at establishing software engineering ethical awareness climate in South African software development environments, including teaching environments. The data collection instrument was pilot tested with few targeted participants to ensure that the respondents interpreted and understood survey questions correctly. Following the pilot test of the data collection instrument, lecturers from two computing departments in a university of technology were individually invited through emails to participate in the study over a period of 6 months. A total of 103 email invites were sent out to staff members of the two departments, however, 44 participated in the online survey, resulting in a response rate of $43 \%$.

A number of questions were posed to participants to determine their level of awareness of software engineering code of ethics. To ensure that respondents were the intended ones, only participants who chose a job description of a university computing lecturer were allowed to respond to the rest of the questions of the survey.

The study used graphical, univariate and bivariate analyses on the collected data in order to provide answers to the research question posed earlier. Due to the limited number of responses, inferential statistics, which could have enriched the findings of this study, was not be applied that. The next discussion presents the research results of the study.

\section{RESEARCH RESULTS}

\section{A. Participants' Profile and Job Descriptions}

Fig. 1 shows the profile of the 44 participants of this study. The data analysis results revealed that the majority (just over $77 \%$ ) of participants were males, while females and those who chose not to specify their gender made up the remainder of the participants. On the other hand, $68.2 \%$ of the respondents were between 30 and 39 years of age, while $18.2 \%$ and $13.6 \%$ 
of them were between 40 and 49 as well as between 50 and 59 years of age respectively, as shown in Fig. 2.

Seventy five percent (75\%) of the participants had a postgraduate qualification; while $18.2 \%$ were holders of a degree qualification (see Fig. 3). The remaining $6.8 \%$ was split amongst participants who had a doctoral degree, a diploma and those who preferred not to divulge their qualifications. According to Fig. 4, the respondents who had more than 10 years of lecturing experience were $29.5 \%$, followed by those who had between 3 and 5 years of work experience at $25 \%$. The staff members who had between 1 and 2 years of work experience made up $15.9 \%$ of the participants, while the lecturers (educators) who had less than 1 year of work experience as well as the ones who had no lecturing experience were $13.6 \%$ each of the respondents.

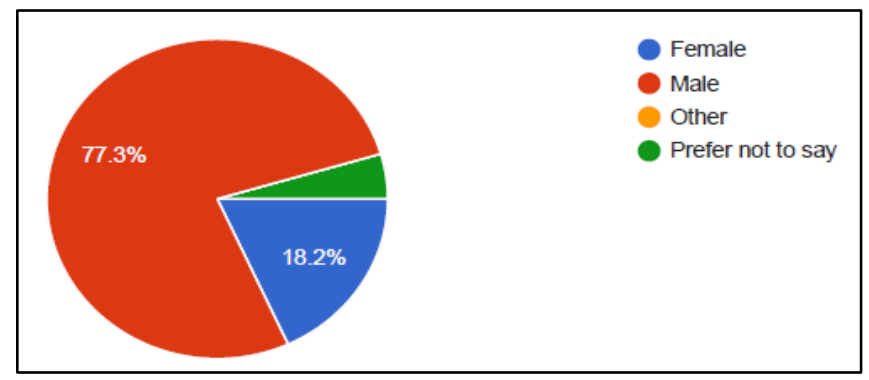

Fig. 1. Gender Distribution of Participants.

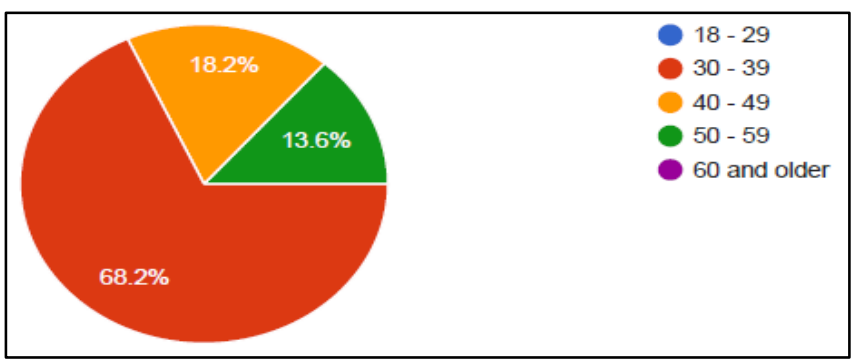

Fig. 2. Age Group of Participants.

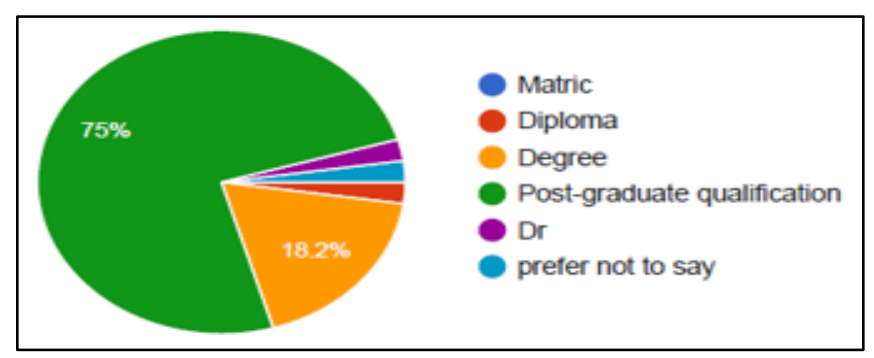

Fig. 3. Qualification Levels of Participants.

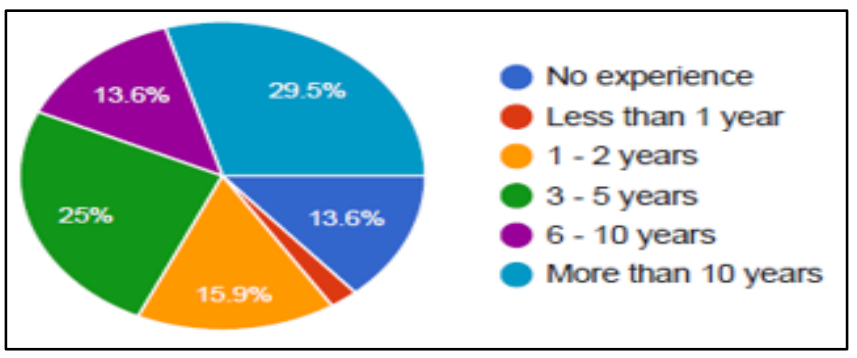

Fig. 4. Work Experience of Participants.
According to Fig. 5, the majority (52.3\%) of the participants were holding lecturer positions, while those who held junior lecturer positions were $36.4 \%$. About nine percent (9.1\%) of the respondents were senior lecturers, while the remaining 2.2\% preferred not to disclose their positions. Since there were participants who chose not to indicate their positions, it is therefore difficult to tell whether the two departments had participants who held professorship positions. If they did, it would have been very few individuals. Fig. 6 shows that only $11.4 \%$ of participants had membership with professional bodies, which included Institute of Electrical and Electronics Engineers (IEEE), Engineering Council of South Africa (ECSA), Institute of IT Professionals South Africa (IITPSA) and International Association of Engineers (IAENG). The notable part of these results is the lack of affiliation of any female educator to the professional organizations, as shown in Table I.

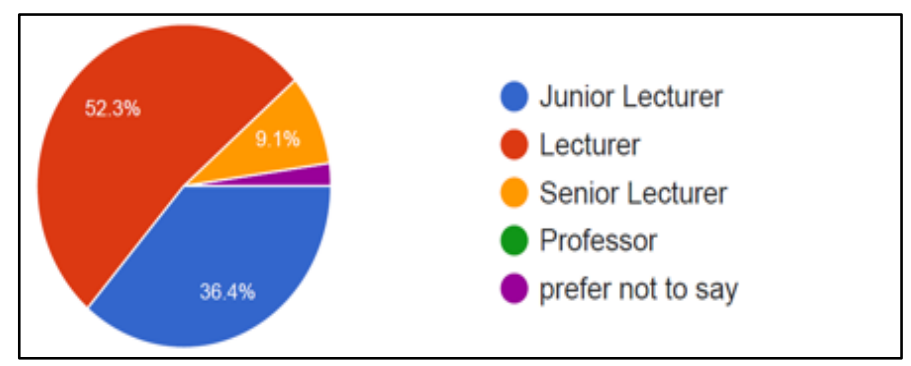

Fig. 5. Job Levels of Participants.

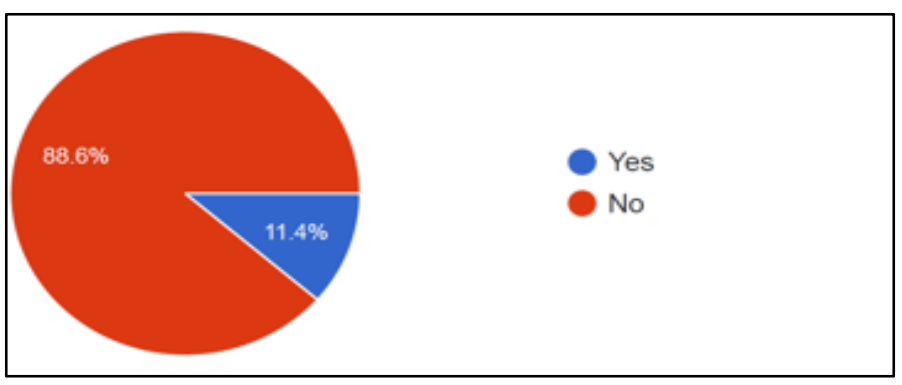

Fig. 6. Membership of Professional Bodies.

TABLE I. MEMBERSHIP OF PROFESSIONAL BODIES

\begin{tabular}{|c|c|c|c|c|}
\hline \multirow{8}{*}{ 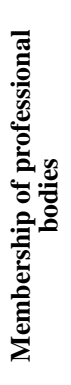 } & Gender & Responses & Frequency & Percentage \\
\hline & \multirow{2}{*}{ Female } & No & 8 & 100 \\
\hline & & Yes & 0 & 0 \\
\hline & \multirow{2}{*}{ Male } & No & 29 & 85.29 \\
\hline & & Yes & 5 & 14.71 \\
\hline & \multirow{2}{*}{$\begin{array}{l}\text { Prefer not } \\
\text { to say }\end{array}$} & No & 2 & 100 \\
\hline & & Yes & 0 & 0 \\
\hline & & Total & 44 & 100 \\
\hline
\end{tabular}

B. The Level of Awareness and Exposure to a Code of Ethics Specific to Software Engineering

This study used the following measurements to gauge the level of awareness and exposure to software engineering code of ethics: 
- Awareness of software engineering unethical incidents reported on the media.

- Previously been made aware of software engineering code of ethics, and if so,

o How and where did the participant become aware?

o Inclusion of software engineering code of ethics in current curriculum.

o Presented software engineering code of ethics related topics. o Inclusion of code of ethics in modules offered by colleagues of respondents.

o Discussions with students about current events related to code of ethics.

o Code of ethics related learning outcomes in the content taught by participants.

The following discussion presents the responses of the participants, as shown in Table II (see next page), for each of the abovementioned measurements of code of ethics awareness.

TABLE II. RESPONSES OF PARTICIPANTS TO QUESTIONS REgARDING THEIR AWARENESS AND EXPOSURE TO SOFTWARE ENGINEERING CODE OF ETHICS

\begin{tabular}{|c|c|c|c|c|c|}
\hline \multirow{33}{*}{ 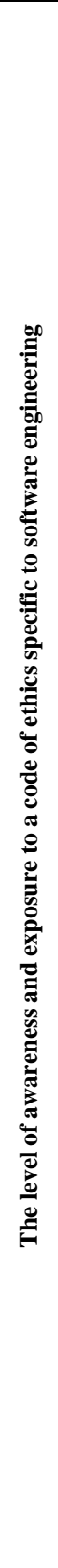 } & Measurements & Responses & Frequency & Percentage & Cumulative \\
\hline & \multirow{3}{*}{$\begin{array}{l}\text { Awareness of software } \\
\text { engineering unethical } \\
\text { incidents reported on media }\end{array}$} & No & 22 & 50 & 50 \\
\hline & & Yes & 22 & 50 & 100 \\
\hline & & Total & 44 & 100 & \\
\hline & \multirow{3}{*}{$\begin{array}{l}\text { Previously been made } \\
\text { aware of software } \\
\text { engineering code of ethics }\end{array}$} & No & 24 & 54.55 & 54.55 \\
\hline & & Yes & 20 & 45.45 & 100 \\
\hline & & Total & 44 & 100 & \\
\hline & \multirow{8}{*}{$\begin{array}{l}\text { How and where did the } \\
\text { awareness occur }\end{array}$} & & & & \\
\hline & & Through self-study and personal development & 6 & 30 & 30 \\
\hline & & Through their tertiary education & 5 & 25 & 55 \\
\hline & & Through short courses or workshops & 4 & 20 & 75 \\
\hline & & Through company policies & 2 & 10 & 85 \\
\hline & & Through membership to external professional bodies & 2 & 10 & 95 \\
\hline & & I don't know or can't remember & 1 & 5 & 100 \\
\hline & & Total & 20 & 100 & \\
\hline & & & & & \\
\hline & \multirow{4}{*}{$\begin{array}{l}\text { Inclusion of software } \\
\text { engineering code of ethics } \\
\text { in current curriculum }\end{array}$} & No: there is no such content in any content & 9 & 45 & 45 \\
\hline & & Yes: it is included in a compulsory course content & 8 & 40 & 85 \\
\hline & & Yes: it is included in an optional or elective course content & 3 & 15 & 100 \\
\hline & & Total & 20 & 100 & \\
\hline & \multirow{3}{*}{$\begin{array}{l}\text { Presented software } \\
\text { engineering code of ethics } \\
\text { related topics }\end{array}$} & No & 10 & 50 & 50 \\
\hline & & Yes & 10 & 50 & 100 \\
\hline & & Total & 20 & 100 & \\
\hline & \multirow{3}{*}{$\begin{array}{l}\text { Inclusion of code of ethics } \\
\text { in modules offered by } \\
\text { colleagues of respondents }\end{array}$} & No & 7 & 35 & 35 \\
\hline & & Yes & 13 & 65 & 100 \\
\hline & & Total & 20 & 100 & \\
\hline & \multirow{4}{*}{$\begin{array}{l}\text { Discussions with students } \\
\text { about current events related } \\
\text { to code of ethics }\end{array}$} & No & 7 & 35 & 35 \\
\hline & & Not sure / Do not remember & 5 & 25 & 60 \\
\hline & & Yes & 8 & 60 & 100 \\
\hline & & Total & 20 & 100 & \\
\hline & \multirow{3}{*}{$\begin{array}{l}\text { Code of ethics related } \\
\text { learning outcomes in the } \\
\text { content taught by } \\
\text { participants }\end{array}$} & No & 6 & 30 & 30 \\
\hline & & Yes & 14 & 70 & 100 \\
\hline & & Total & 20 & 100 & \\
\hline
\end{tabular}


1) Awareness of software engineering unethical incidents reported on media: The respondents were split in the middle in their responses on their awareness of unethical incidents reported on the media $-50 \%$ said they were aware, whereas the other $50 \%$ claimed they were not aware.

2) Previously been made aware of software engineering code of ethics: The majority of the participants (54.5\%) indicated that they were previously not made aware of the code of ethics pertaining to software engineering, while the remaining $45.5 \%$ percent said they were made aware. Those who indicated that they were made aware were asked followup questions, whose answers are presented next. When the results were interrogated little further, the indication was that, senior staff members (lecturers and senior lecturers) were the most ones (18 of the $27=67 \%$ of them combined) who were not previously aware of software engineering code of ethics, as shown in Table III.

3) How and where did the awareness occur: Thirty percent (30\%) of the participants said they became aware through self-study and personal development, while $25 \%$ of the respondents said they became aware through their tertiary education (see Fig. 7). Twenty percent (20\%) of the respondents said they were made aware through short courses or workshops that they attended, while $10 \%$ of each of the remaining $20 \%$ indicated that company policies and membership to external professional bodies played a role in the awareness process respectively. The remaining 5\% said they could not remember or did not know.

4) Inclusion of software engineering code of ethics in current curriculum: Sixty percent $(60 \%)$ of the participants indicated that the code of ethics or any topics related to it were not included in the courses/modules that the participants were involved in (45\% of the participants) or if it was included, it was included in an elective module (15\% of the participants). Forty percent $(40 \%)$ purported that it was included in a compulsory course content.

5) Presented software engineering code of ethics related topics: The respondents were split in the middle $-50 \%$ said they once conducted a lesson on software engineering code of ethics related topic(s), while the other 50\% indicated that they never did.

TABLE III. LEVEL OF ETHICAL AWARENESS By Job LEVEL

\begin{tabular}{|c|c|c|c|c|}
\hline \multirow{10}{*}{ 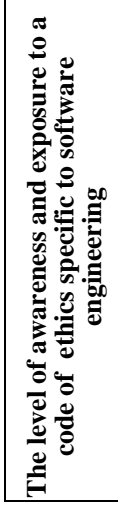 } & Job level & Responses & Frequency & Percentage \\
\hline & \multirow{2}{*}{$\begin{array}{l}\text { Junior } \\
\text { lecturer }\end{array}$} & No & 6 & 37.50 \\
\hline & & Yes & 10 & 62.50 \\
\hline & \multirow{2}{*}{ Lecturer } & No & 15 & 65.22 \\
\hline & & Yes & 8 & 34.78 \\
\hline & \multirow{2}{*}{$\begin{array}{l}\text { Senior } \\
\text { lecturer }\end{array}$} & No & 3 & 75 \\
\hline & & Yes & 1 & 25 \\
\hline & \multirow{2}{*}{$\begin{array}{l}\text { Prefer not to } \\
\text { say }\end{array}$} & No & 0 & 0 \\
\hline & & Yes & 1 & 100 \\
\hline & & Total & 44 & 100 \\
\hline
\end{tabular}

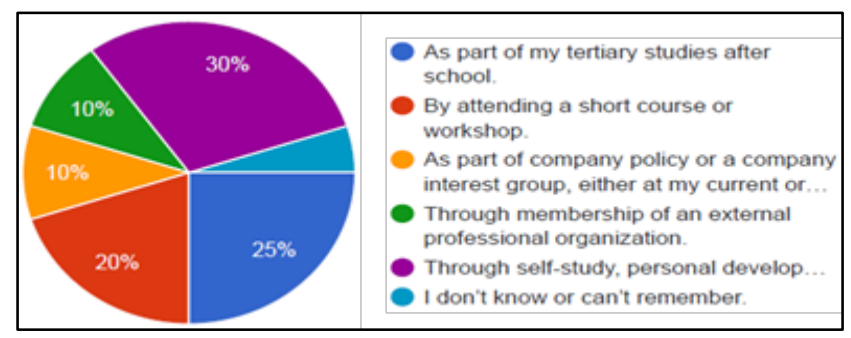

Fig. 7. Source of Ethics Awareness for Participants.

6) Inclusion of code of ethics in modules offered by colleagues of respondents: The majority (65\%) of the participants said that they were aware that subjects that were offered by their colleagues had content on software engineering code of ethics, while $35 \%$ of the participants mentioned that they were unaware of such inclusion.

7) Discussions with students about current events related to code of ethics: Only $40 \%$ of the respondents could confirm that they had discussions with their students on recent (last 12 months) events related to software engineering code of ethics or code breaches. Sixty percent (60\%) either never had such discussions (35\%) or were not sure or could not remember (25\%).

8) Code of ethics related learning outcomes in the content taught by participants: Seventy percent $(70 \%)$ of the respondents mentioned that they were aware of software engineering code of ethics related learning outcomes (LOs) in the content they taught, while on the other hand, $30 \%$ of the participants were not aware of such LOs.

\section{Discussion OF Research Results}

\section{A. Participants' Gender, Age and Job Profile}

The gender and age profile of participants show that the workforce in the two departments, have high gender imbalances and the workforce is relatively young. The job profile of the respondents indicates that the majority (70.5\%) of them held lecturer positions and had no more than 5 years of experience and thus relatively inexperienced. These results should be expected given that the educators were relatively young as mentioned above. Almost $90 \%$ of the participants (including all female participants who identified themselves as such) were not members of any professional organization, which promote software code of ethics. Even though these figures are better than those mentioned in a study by Rogerson [52] they are still a cause for concern. This should be worrying because there are (should be) benefits (such as developing code of ethics awareness and individual development) for belonging to such professional bodies. However, the role of the professional bodies in providing code of ethics awareness to their members seems to be minimal given the fact that the results of this study show that only $10 \%$ of those who had subscription with these professional organizations received ethical awareness through them. This calls for improved code of ethical awareness campaigns from the professional organizations. Moreover, the professional organizations should have targeted drive to recruit female members. 


\section{B. The Level of Awareness and Exposure to Software Engineering Ethics Code}

The survey results of this study show that more than half (54.5\%) of the educators were not aware of software engineering code of ethics prior to this study, yet they are entrusted with the responsibility of educating students on the same code of ethics. Moreover, the analysis results revealed that the majority of the academics who were unaware of code of ethics held lecturer and senior lecturer positions (see Table III), which should be a concern given that these educators should be the guiding figures on issues of ethics. How can an educator, who is not aware of ethics, be able to lead a student to develop competent ethical reasoning? Furthermore, half of the academics were not aware of media reports of unethical incidents, and this should be worrying because a knowledge of such incidents should enable educators to practicalise the concept of ethics in lecture halls, thus allowing students to internalize and relate with the concept much better. Relating the incidents to students would help ease the difficulty of teaching ethics concepts to students. The awareness and knowledge of unethical incidents would not only demonstrate knowledge of violated principles prescribed by the codes of ethics, but would also assist in leading students through the ethical analysis learning process, as indicated by [35]. The lack of awareness of ethics code could mean such educators are unable to link ethics to practical day-to-day happenings that involve issues of software engineering code of ethics, resulting in failure to make students aware of their ethical responsibility as future software engineers.

There were three leading sources of awareness for the academics who were aware of software engineering code of ethics, and these were self-study and personal development (30\%), tertiary education (25\%) and short courses or workshops (20\%). The organizational policies and professional organizations accounted for $10 \%$ each. However, even though tertiary education was amongst the three leading sources of code of ethics awareness it only accounted for a mere $25 \%$, thus showing that tertiary education has little impact in this regard, bringing into question the level of coverage of software engineering code of ethics by our institutions. The majority (60\%) of the educators indicated that the code of ethics or topics related to it were not included in the courses/modules that the participants were involved in ( $45 \%$ of the participants) or if it was, it was included in elective modules (15\% of the participants). This finding and our observation on ethics coverage by our institutions of higher learning concur with the findings by Marebane and Hans [53] that the coverage of software engineering code of ethics by computing curricula of South African UoTs is inadequate. The preceding discussion has also brought into spotlight the lack of awareness of the code of ethics by the educators who are expected to be crusaders of the awareness campaign. It could also be possible that even though the code of ethics is covered by some modules/subjects in the institutions' curricula (65\% of the educators indicated that code of ethics was covered by modules offered by their colleagues), but due to educators' lack of awareness (knowledge) of the code of ethics then the code of ethics topics do not get covered in the teaching. The results also show that of those that were aware of the code of ethics, only $50 \%$ (10 educators) of them ever lectured on the subject, meaning that 34 educators were either not aware of the code of ethics (24 educators) or never presented any lecture on code of ethics (10 educators). Another indication that code of ethics seems not to be receiving necessary attention from the educators is the fact that only $40 \%$ of those who were aware of code of ethics had a discussion in the last 12 months on code of ethics related events, the other $60 \%$ either never had a discussion or could not recall. An interesting finding of this study is that even though $70 \%$ of those who were aware of code of ethics knew about the learning outcomes in the content they taught only $50 \%$ of them ever presented a lecture on the subject, yet another signal of inadequate coverage of the topic by the educators. These findings reveal and confirm that indeed software engineering education receive marginal attention from our educators and curricula, as also purported by [18].

\section{CONCLUSION}

This study set to answer and meet the following research question and objective respectively:

- What is the computing academics' level of awareness and exposure to a code of ethics specific to software engineering?

- To determine computing academics' level of awareness and exposure to a code of ethics specific to software engineering.

Two major findings of this study, which were presented in the previous section provided an answer to the study's research question and also met its objective. The two findings are:

- The worrying lack of awareness or exposure on software engineering ethics codes by the majority of the educators before this research study. This may be the possible cause for such lecturers not to be able to recognise the importance of including ethics in their curriculum, if they do include, they may fail to teach the principles contained in the codes sufficiently. Secondly, this lack of awareness may inhibit or disable the lecturers' ethical radar. Unfortunately, tertiary education played a minor role in educating lecturers (who were once junior students) on principles of software engineering code of ethics. This brings into question the level of coverage of code of ethics by tertiary institutions in their computing programmes. What makes this question even more valid and solid is that majority of the educators mentioned that software engineering code of ethics or topics related to it were either not included in the courses/modules that the participants were involved or were included in elective modules

- Half of the academics were not aware of unethical incidents that were reported on media. This could be the consequence of a disabled ethical radar, which subsequently will prevent lecturers from using such practical examples in their teaching, consequently 
depriving students from learning from practical examples.

The concern that these findings highlight is the fact that the same educators who lack awareness of code of ethics are expected to be at the forefront of making students aware of the same codes they knew little about. This limits the ability to practicalise and relate the incidents to the curriculum and codes of ethics. How can they effectively fulfil their moral development educators' role of teaching ethics in technology courses, and to promote the ethicality of the profession when they lack ethical awareness? It is an imaginable expectation that academics who are entrusted with the responsibility of teaching students on the concepts of code of ethics of a profession are themselves in need of such education. To remedy the situation, institutions of higher learning should initiate or promote activities for professional code of ethics awareness for computing lecturers. Furthermore, lack of awareness by educators is likely to graduate software engineers who will fail to behave ethically and degrade the public view of the profession. Collaboration between universities and software engineering professional bodies on ethical practices and accrediting courses for software engineers can significantly improve awareness and ethical practices in the training of future software engineers.

\section{LIMITATIONS AND FUTURE STUDIES}

The results of this study are based on self-reporting from participants and this has a possibility of biasness. It was also indicated in Section 4 that the number of responses to this study made it difficult to use inferential statistical, which could enrich the findings of the study, however this presents an opportunity for possible future study, which fulfils this requirement.

\section{REFERENCES}

[1] Huff and A. Furchert, "Computing Ethics Toward a Pedagogy of Ethical Practice,” Commun. ACM, vol. 57, no. 7, pp. 25-27, 2014, doi: $10.1145 / 2618103$.

[2] C. Fiesler, N. Garrett, and N. Beard, "What dowe teach whenwe teach tech ethics? a syllabi analysis,” Annu. Conf. Innov. Technol. Comput. Sci. Educ. ITiCSE, pp. 289-295, 2020, doi: 10.1145/3328778.3366825.

[3] IEEE-CS, "Code of Ethics |IEEE-CS/ACM Joint Task Force on Software Engineering Ethics and Professional Practices,” 1999. [Online]. Available: https://www.computer.org/education/code-ofethics.

[4] S. Joseph, "Social Media, Political Change, and Human Rights Recommended Citation SOCIAL MEDIA, POLITICAL CHANGE, AND HUMAN RIGHTS,” Boston College Int. Comp. Law Rev., vol. 35, no. 1, pp. 1-1, 2012, [Online]. Available: http://lawdigitalcommons.bc.edu/iclrhttp://lawdigitalcommons.bc.edu/icl $\mathrm{r} / \mathrm{vol} 35 / \mathrm{iss} 1 / 3$.

[5] T. Lecklider, "Autonomous mining equipment years ahead of car development,” Evaluation $\quad 2017$. https://www.evaluationengineering.com/test-issues-

techniques/technology/machine-vision/article/13015150/autonomousmining-equipment-years-ahead-of-car-development (accessed Feb. 13, 2021).

[6] L. Joskowicz, "Computer-aided surgery meets predictive, preventive, and personalized medicine,” EPMA J., vol. 8, no. 1, pp. 1-4, 2017, doi: 10.1007/s13167-017-0084-8.

[7] K. Jha, A. Doshi, P. Patel, and M. Shah, "A comprehensive review on automation in agriculture using artificial intelligence," Artif. Intell. Agric., vol. 2, pp. 1-12, 2019, doi: 10.1016/j.aiia.2019.05.004.

[8] A. Rashid, J. Weckert, and R. Lucas, "Software engineering ethics in a digital world,” Computer (Long. Beach. Calif)., vol. 42, no. 6, pp. 34 41, 2009, doi: 10.1109/MC.2009.200.

[9] A. Buncombe, "Boeing 737 MAX: Company reveals new software problem detected in jets which 'must be fixed before planes can fly,", Independent News, 2019. https://www.independent.co.uk/news/world/americas/boeing-737-maxjets-ceo-new-software-problem-a8855841.html (accessed Jun. 03, 2019).

[10] G. Travis, "How the Boeing 737 Max Disaster Looks to a Software Developer," IEEE Spectr., pp. 1-10, 2019, [Online]. Available: https://spectrum.ieee.org/aerospace/aviation/how-the-boeing-737-maxdisaster-looks-to-a-software-developer.

[11] United Nations, "Human Rights Council Thirty-ninth session 10-28 September 2018 Agenda item 4 Human rights situations that require the Council's attention Report of the independent international fact-finding mission on Myanmar," 2018

[12] C. Wardle and E. Singerman, "Too little, too late: Social media companies' failure to tackle vaccine misinformation poses a real threat," BMJ, vol. 372, 2021, doi: 10.1136/bmj.n26.

[13] C. Hanchey, "Yes, you can teach ethics!,” J. Comput. Sci. Coll., vol. 17, no. 4, pp. 145-153, 2002.

[14] F. Ahmad, "Computer Science \& Engineering Curricula and Ethical Development," in International Conference on Teaching and Learning in Computing and Engineering, 2014, pp. 220-225, doi: 10.1109/LaTiCE.2014.50.

[15] C. D. Martin and W. C. Huff, "A Conceptual and Pedagogical Framework,” in Proceedings Frontiers in Education 1997 27th Annual Conference. Teaching and Learning in an Era of Change, 1997, vol. 1, pp. 479-483.

[16] C. Huff and D. Martin, "Computing Consequences: A framework for teaching ethical computing,” Commun. Acm, vol. 38, no. 12, pp. 75-84, 1995.

[17] A. Barnard, C. de Ridder, L. Pretorius, and E. Cohen, "Integrating Computer Ethics into the Computing Curriculum: A Framework for Implementation,” Proc. 2003 InSITE Conf., no. June, 2003, doi: $10.28945 / 2619$.

[18] J. Jia and J. Xin, "Integration of ethics issues into software engineering management education,” ACM Int. Conf. Proceeding Ser., pp. 33-38, 2018, doi: 10.1145/3210713.3210725.

[19] E. Towell, "Teaching ethics in the software engineering curriculum," in Software Engineering Education Conference, Proceedings, 2003, vol. 2003-Janua, pp. 150-157, doi: 10.1109/CSEE.2003.1191372.

[20] D. Gotterbarn, "How the new Software Engineering Code of Ethics affects you," IEEE Softw., vol. 16, no. 6, pp. 58-64, 1999, doi: $10.1109 / 52.805474$.

[21] J. H. Moor, "What is computer ethics?," Metaphilosophy, vol. 16, no. 4, pp. 266-275, 1985, doi: 10.1007/BF00882026.

[22] J. Johnson, "Teaching Ethics to Science Students: Challenges and a Strategy," in Education and Ethics in the Life Sciences: Strengthening the Prohibition of Biological Weapons, B. Rappert., B. Rappert, Ed. Canberra: ANU E Press, 2010.

[23] L. Kohlberg and R. H. Hersh, "Moral Development: A Review of the Theory," vol. 16, no. 2, pp. 53-59, 1977, doi: 10.1146/annurev.ecolsys.3.

[24] K. Muskavitch, "Cases and goals for ethics education,” Sci. Eng. Ethics, vol. 11, no. 3, pp. 431-434, 2005, doi: 10.1007/s11948-005-0011-6.

[25] M. Huyck, D. Ferguson, J. Ferrill, L. Getzler-Linn, and M. Raber, "Work in progress - Enhancing ethical awareness within undergraduate multidisciplinary teams by preparing Codes of Ethics," Proc. - Front. Educ. Conf. FIE, no. 978, pp. 21-23, 2008, doi: 10.1109/FIE.2008.4720383.

[26] A. Harris and M. Lang, "Incorporating Ethics and Social Responsibility in IS Education.,” J. Inf. Syst. Educ., vol. 22, no. 3, pp. 183-190, 2011, [Online]. Available: http://search.ebscohost.com/login.aspx?direct=true\&profile=ehost\&scop $\mathrm{e}=$ site\&authtype $=$ crawler\&jrnl $=10553096 \& \mathrm{AN}=69713585 \& \mathrm{~h}=2$ IqrlxqA X3mY6CMHvX7E3jmFeST2qp7NoJEez765uemfcuUJ2gixNWDj\%2F2 10iDZ0h1QTbbo\%2FH1\%2FdGOKV2HOnCQ\%3D\%3D\&crl=c.

[27] E. Towell and J. B. Thompson, "A further exploration of teaching ethics 
in the software engineering curriculum," in Software Engineering Education Conference, Proceedings, 2004, vol. 17, pp. 39-44, doi: 10.1109/csee.2004.1276508.

[28] M. Skirpan, N. Beard, S. Bhaduri, C. Fiesler, and T. Yeh, "Ethics education in context: A case study of novel ethics activities for the CS classroom,” SIGCSE 2018 - Proc. 49th ACM Tech. Symp. Comput. Sci. Educ., vol. 2018-Janua, pp. 940-945, 2018, doi: $10.1145 / 3159450.3159573$

[29] Y. Al-Saggaf and O. K. Burmeister, "Improving skill development: An exploratory study comparing a philosophical and an applied ethical analysis technique," Comput. Sci. Educ., vol. 22, no. 3, pp. 237-255, 2012, doi: 10.1080/08993408.2012.721073.

[30] T. C. Lethbridge, R. J. Leblanc, A. E. Kelley Sobel, T. B. Hilburn, and J. L. Diaz-Herrera, "SE2004: Recommendations for undergraduate software engineering curricula," IEEE Softw., vol. 23, no. 6, pp. 19-25, 2006, doi: 10.1109/MS.2006.171.

[31] ACM/IEEE, "SE 2014: Curriculum Guidelines for Undergraduate Degree Programs in Software Engineering," Computer (Long. Beach. Calif)., vol. 48, no. 11, pp. 106-109, 2015, doi: 10.1109/mc.2015.345.

[32] H. T. Tavani, "Curriculum issues and controversies in computer ethics instruction,” Int. Symp. Technol. Soc. Proc., vol. 2001-Janua, pp. 41-50, 2001, doi: 10.1109/ISTAS.2001.937720.

[33] J. E. Monzon and A. Monzon-wyngaard, "Ethics and Biomedical Engineering education: the continual defiance," in 31st Annual International Conference of the IEEE Engineering in Medicine and Biology Society, 2009, pp. 2011-2014.

[34] R. Reich, M. Sahami, J. M. Weinstein, and H. Cohen, "Teaching computer ethics: A deeply multidisciplinary approach,” Annu. Conf. Innov. Technol. Comput. Sci. Educ. ITiCSE, pp. 296-302, 2020, doi: 10.1145/3328778.3366951.

[35] Z. Khallouf, "About Integrating Ethics in The Software Engineering Curriculum Engineering Curriculum,” 2007.

[36] D. M. Berry and B. Berenbach, "Ethics test results before and after ethics training: A disturbing experience," SwSTE2010 IEEE Int. Conf. Softw. Sci. Technol. Eng., pp. 70-76, 2010, doi: 10.1109/SwSTE.2010.16.

[37] S. Valentine and T. Barnett, "Ethics code awareness, perceived ethical values, and organizational commitment," J. Pers. Sell. Sales Manag., vol. 23, no. 4, pp. 359-367, 2003, doi: 10.1080/08853134.2003.10749009.

[38] J. Ballantine, M. Levy, A. Martin, I. Munro, and P. Powell, "An ethical perspective on information systems evaluation,” Int. J. Agil. Manag. Syst., vol. 2, no. 3, pp. 233-241, 2000, doi: 10.1108/14654650010356149.

[39] K. Munro and J. Cohen, "Ethical Behavior and Information Systems Codes: The Effects of Code Communication, Awareness, Understanding, and Enforcement,” ICIS 2004 Proc., 2004.

[40] J. R. Córdoba, "Developing ethical awareness in information systems practice: A Foucaultavian view,” J. Information, Commun. Ethics Soc., vol. 4, no. 4, pp. 181-190, 2006, doi: 10.1108/14779960680000291.

[41] C. D. Martin and E. Y. Weltz, "From Awareness to Action : Integrating
Ethics and Social Responsibility into the Computer Science Curriculum,” ACM SIGCAS Comput. Soc., vol. 29, no. 2, pp. 6-14, 1999.

[42] S. H. Wilford and K. J. Wakunuma, "Perceptions of ethics in IS: How age can affect awareness,” J. Information, Commun. Ethics Soc., vol. 12, no. 4, pp. 270-283, 2014, doi: 10.1108/JICES-02-2014-0013.

[43] L. N. K. Leonard, T. P. Cronan, and J. Kreie, "What influences IT ethical behavior intentions - Planned behavior, reasoned action, perceived importance, or individual characteristics?,” Inf. Manag., vol. 42, no. 1, pp. 143-158, 2004, doi: 10.1016/j.im.2003.12.008.

[44] M. E. Brown, L. K. Treviño, and D. A. Harrison, "Ethical leadership: A social learning perspective for construct development and testing," Organ. Behav. Hum. Decis. Process., vol. 97, no. 2, pp. 117-134, 2005, doi: 10.1016/j.obhdp.2005.03.002.

[45] M. Schwartz, "The nature of the relationship between corporate codes of ethics and behaviour,” J. Bus. Ethics, vol. 32, no. 3, pp. 247-262, 2001, doi: 10.1023/A:1010787607771

[46] D. M. Mayer, M. Kuenzi, R. Greenbaum, M. Bardes, and R. (Bombie) Salvador, "How low does ethical leadership flow? Test of a trickle-down model," Organ. Behav. Hum. Decis. Process., vol. 108, no. 1, pp. 1-13, 2009, doi: 10.1016/j.obhdp.2008.04.002.

[47] P. Y. Cheng, "University Lecturers' Intention to Teach an Ethics Course: A Test of Competing Models,” J. Bus. Ethics, vol. 126, no. 2, pp. 247-258, 2015, doi: 10.1007/s10551-013-1949-y.

[48] M. Masrom, Z. Ismail, and R. Hussein, "Computer ethics awareness among undergraduate students in Malaysian higher education institutions," in 19th Australasian Conference on Information Systems, 2008, pp. 628-637.

[49] M. Aliyu, N. A. O. Abdallah, N. A. Lasisi, D. Diyar, and A. M. Zeki, "Computer security and ethics awareness among IIUM students: An empirical study," in Proceeding of the 3rd International Conference on Information and Communication Technology for the Moslem World: ICT Connecting Cultures, ICT4M 2010, 2010, pp. A52-A56, doi: 10.1109/ICT4M.2010.5971884.

[50] D. Bairaktarova and A. Woodcock, "Engineering Student's Ethical Awareness and Behavior: A New Motivational Model," Sci. Eng. Ethics, vol. 23, no. 4, pp. 1129-1157, 2017, doi: 10.1007/s11948-0169814-X.

[51] L. Cilliers, "Evaluation of information ethical issues among undergraduate students: An exploratory study," South African J. Inf. Manag., vol. 19, no. 1, pp. 1-6, 2017.

[52] S. Rogerson, "Rebooting ethics education in the digital age." pp. 1-4, 2021, [Online]. Available: https://dora.dmu.ac.uk/bitstream/handle/2086/20613/Rebooting ethics education in the digital age prepublication version.pdf?sequence $=2 \&$ isAllowed $=y$.

[53] S. M. Marebane and R. T. Hans, "International Journal of Advanced Computer Science and Applications (IJACSA)," Competency Gap Undergrad. Comput. Qualif. within South African Univ. Technol., vol. 12, no. 4, 2021. 